Article

\title{
Towards a Situational Understanding of Collective Learning: A Reflexive Framework
}

\author{
Seppe De Blust ${ }^{1, *}$, Oswald Devisch ${ }^{2}$ and Jan Schreurs ${ }^{1}$ \\ ${ }^{1}$ Research Unit Planning and Development, Department of Architecture, KU Leuven, 3001 Heverlee, Belgium; \\ E-Mails: seppe.deblust@kuleuven.be (S.D.B.), jan.schreurs@kuleuven.be (J.S.) \\ 2 Department of Architecture \& Art, University of Hasselt, 3590 Diepenbeek, Belgium; E-Mail: oswald.devisch@uhasselt.be \\ * Corresponding author
}

Submitted: 2 July 2018 | Accepted: 14 September 2018 | Published: 24 January 2019

\begin{abstract}
Based on an in-depth study of how socially innovative processes are collectively reinforced within two cases, this article builds a reflexive framework that conceptualizes socially innovative processes as situated trajectories of collective learning. The framework starts from three theories in the field of pedagogy and organisational studies that try to contextualise and operationalise how internal processes of learning, supportive relationships and external demands interrelate within processes of collective learning. In line with the reflexive character of social innovation research, the article presents the framework as a means to give concrete answer on how socially innovative processes can be supported and how the dynamic character of their collective learning trajectories can be managed. The conclusion of this article further reflects on the importance of a situational and multi-layered understanding of collective learning for creating institutional support for socially innovative processes in planning and presents reflexive questions that can help external actors as planning practitioners to position themselves within this often messy and complex reality.
\end{abstract}

\section{Keywords}

collective learning; reflexivity; situational understanding; socially innovative planning

\section{Issue}

This article is part of the issue "The Transformative Power of Urban Planning through Social Innovation", edited by Torill Nyseth (UiT, The Arctic University of Norway, Norway) and Abdelillah Hamdouch (University of Tours, France).

(C) 2019 by the authors; licensee Cogitatio (Lisbon, Portugal). This article is licensed under a Creative Commons Attribution 4.0 International License (CC BY).

\section{Introduction: Social Innovation and Collective Learning}

Planning practice could play a crucial role in creating institutional support for socially innovative action (MacCallum, Moulaert, Hillier, \& Vicari Haddock, 2009; Moulaert \& Cabaret, 2006; Van Dyck \& Van den Broeck, 2013). The transformative aims of planning (Albrechts, 2015; Friedmann, 2011) and its often immanent position in between government and civil society (Albrechts, 2012) creates the opportunity for planning practice to influence and support the processes of learning, decisionmaking, collective action and institutionalization that are crucial for socially innovative action (Jessop, Moulaert,
Hulgård, \& Hamdouch, 2013; Novy, Hammer, \& Leubolt, 2009; Oosterlynck, Van den Broeck, Albrechts, Moulaert, \& Verhetsel, 2011). Notwithstanding this promising basis, the socializing nature of a lot of planning initiatives (a.o., Swyngedouw, 2008) and the underlying variety of conflicting interests, often result in exactly the opposite. Well-intended actions as participatory decisionmaking, co-productive visioning or a need-based understanding of local dynamics, often fail to fully understand and support the open, multiple, and critical nature of a lot of socially innovative initiatives in their search for alternative development strategies (Moulaert, MacCallum, Mehmood, \& Hamdouch, 2013) and end up in strengthening the co-optation of alternative practices by classic 
government systems (see, among others, Kaethler, De Blust, \& Devos, 2017; Palmås \& von Busch, 2015). In this article we argue that a better understanding of the underlying process of collective learning is primordial in order for planning practice to play a role in supporting social innovation. More specifically we plea to conceptualize these trajectories of collective learning as situated and multi-layered trajectories that sometimes support, and other times obstruct one another and that are embedded in larger institutional fields.

Collective learning can best be described as a concept that gives insight in how a diverse group of individuals work on processes of shared problematization and a shared sense of meaning (De Laat \& Simons, 2002; Schreurs \& Kuhk, 2017; Wildemeersch, 2007). Theories of collective learning concretizes how these processes are structured and how they deal with internal complexity and external demands by analysing how a collective emerges, learns and transforms (Whatmore, 2009). In social innovation studies collective learning is seen as a core element for collective transformative action (see, among others, Chambon, David, \& Devevey, 1982; Jessop et al., 2013). Collective learning creates the possibility to collectively appropriate, deconstruct and reconstruct information and knowledge, taking into account a diverse set of life-worlds and value alternatives for existing dominant positions. Social innovation theory starts from the idea that collective learning based on a shared social innovative agenda is crucial in order to recreate existing institutions and structures and provide them with new meanings (Cassinari \& Moulaert, 2014; Jessop et al., 2013; Moulaert \& Nussbaumer, 2005).

The social learning tradition of planning theory and practice (e.g., Friedmann, 1987; Healey, 2009; Kuhk, Schreurs, \& Dehaene, 2015; Vandenabeele, Vanassche, \& Wildemeersch, 2011) share this understanding of learning as a crucial element for transformative action. Social learning values the social processes of knowledgecreation and the construction of goals as the result of a "continuous socially situated activity in probing inquiry, collective sense-making and the testing out of ideas to see if they 'work' and mobilise attention" (Healey \& Hillier, 2008, p. xvii; see also Healey, 2013). Where both planning and social innovation studies share the idea of appropriate qualities for learning, a process of learning should be inclusive, reflective, subjectifying, has a transformative potential and starts from an interdisciplinary, transdisciplinary and iterative endeavour (e.g., Brown \& Lambert, 2013; Kuhk et al., 2015; Moulaert, Van Dyck, Khan, \& Schreurs, 2013; Servillo \& Schreurs, 2013), the specific application of which remains rather diverse.

In planning there is a focus on the shared endeavour of dealing with irreducible uncertainty (Bertolini, 2010; Schreurs \& Kuhk, 2017), where the social innovation approach has a much more political understanding of learning. Social innovation theory defines collective learning as "a new form of social learning oriented to the production of knowledge as an 'intellectual common'" (Jessop et al., 2013, p. 119). Collective learning emphasizes on the solidarity-based character of learning through processes of sharing and cooperation in order to organize the satisfaction of human needs and changes in social relations and increasing the socio-political capability as well as access to resources of a large diversity of unheard actors (Moulaert, Martinelli, Swyngedouw, \& Gonzalez, 2005). The transdisciplinary character of collective learning becomes an important asset to relate the revalorization of a large diversity of social use values with-much needed-institutional support (Jessop et al., 2013).

In order to avoid that these different interpretations of learning create confusion and consequently an unpredictable basis for supporting socially innovative initiatives and lead to their (un)intentional co-optation and depoliticization in planning processes, we propose to focus on a more operational and situated understanding of collective learning-later defined as a reflexive framework. This understanding goes beyond the qualities of learning and engages with a more in-depth understanding of how processes of collective learning are managed, how internal processes of learning and external demands interrelate and how external actors as planning practitioners can play a role in creating the institutional support for collective learning processes. We define this perspective as an actor-oriented approach to collective learning as it focuses on the dynamic collection of actors (that can change in composition), and how they are part of multiple collectives and have to deal with contradictions, own agenda's, or parallel trajectories. Based on this understanding we try to define certain reflexive questions that can help external agents as spatial planning practitioners to better define their role and added value in collective learning trajectories in order to strengthen their resistance to (un)intentional co-optation and de-politicization in planning processes.

In the following paragraphs we give an overview of the different methodological steps that were applied while constructing the framework, conducting casebased research and defining the final reflexive questions. Following this overview, we introduce the reflexive framework that was drafted during this research and describe shortly its separate underlying theories. In the third part of this article we describe the situated trajectories of collective learning of two cases: the living Streets in Ghent and the Eastern Rail Park (PSO) in Antwerp, Belgium. Both cases can be described as civil society led processes and have socially innovative potential. Where in the case of the Living Streets, an example of temporary use of public space, this potentiality evolved towards a culture of cooperation between different organizations and a further institutionalization of socially innovative practices, conflictual tensions remained the institutional basis for collective learning in the case of PSO, an example of local advocacy planning. In the conclusions of this article we further illustrate the added value of our reflexive framework and introduce how the analysis of both cases lead to a multi-layered understanding of collective 
learning for planning practitioners in supporting local socially innovative initiatives.

\section{Methodology}

The research trajectory consisted of a series of workshops on participatory cases that we organized for the professional association of spatial planners in Flanders (VRP). Three sessions were organized with key stakeholders of different cases and a group of professional spatial planners that worked for different cities in Flanders, for the Flemish government or for private developers. In the first two sessions, key stakeholders presented six case studies of different collective learning trajectories that worked on social innovation and participation in planning on different scales. At the end of each presentation, the stakeholders and planning practitioners were asked to map the capabilities that the collectives needed to achieve their goals, based on the theoretical framework of Baser and Morgan (2008), as will be later described. In the third session, the work of Biesta (2010, 2011, 2012) on the functions of education and learning and the work of Bruno Latour (2004) on onto-political proceedings were introduced-the two other theories behind our reflexive framework after Baser and Morgan (2008) and a reflection on the changing position of spatial planning practitioners was presented. Based on the three theories and the collective mapping exercises of the first two sessions, a reflection was organized to gain a better understanding of the cases based on both the internal process of collective learning and its (un)supportive relationships with external agents as spatial planning practitioners. As a result of this reflection, first drafts of the reflexive framework were developed and reflexive questions for planning practitioners were discussed and presented.

In a second part of the research, the three authors of the article further developed the reflexive framework by researching two case studies more in-depth. Both case studies were selected because of their socially innovative potential (combining local action with processes of institutionalisation) but different outcome (a culture of cooperation versus conflictual tension). Based on the presentations of both case studies during the first sessions of our research and the initial mapping of collective capabilities, follow-up interviews were organized with the main key stakeholders of the cases. These follow-up interviews were structured based on the same questions and theories that arose in the three sessions. Firstly, we critically evaluated and validated the mapping of collective capabilities of the cases. Based on this mapping we further reflected on the trajectory of collective learning and the relationship with planning practitioners following the theoretical frameworks presented in the following paragraphs and their related questions. The semi-structured interviews were compared and analysed in such way that they could further specify and critically evaluate the interrelation between the different theories of the framework and its relation with social innovation. In order to relate the results of this research to planning practice, we tried, inspired by the reflexive exercise in the last session of the participation lab, to rephrase the results and observations to clear reflexive questions that could help spatial planning practitioners to position themselves in relation to collective learning trajectories and their socially innovative potential.

\section{Towards a Framework}

The reflexive framework is based on a selection of three theories that, in our understanding, can help to operationalize our understanding of collective learning. These theories are situated in the field of pedagogy or organizational studies and, consequently, are not directly developed with the aim to support social innovation in the context of spatial planning projects. The three theories that we discussed are the work of Baser and Morgan (2008) on capacity development, the work of Gert Biesta (2010) on the functions of education and learning, and the work of Bruno Latour (2004) on onto-political proceedings. Each of the theories shed light on a specific element of an operational and situational understanding of collective learning.

The work of Baser and Morgan (2008) and their study on capacity building can be used to understand how processes of collective learning are managed, by describing five core collective capabilities that define the ability of a group to organize themselves. In this respect these capabilities should allow to learn how the organization can adapt to conflicting goals and an evolving situation. Baser and Morgan (2008, p. 33) describe five core collective capabilities that can, to a greater or lesser extent, be found in all organizations and systems: capabilities (1) to commit and engage, (2) to carry out functions or tasks, (3) to relate and attract resources and support, (4) to adapt and self-renew, and (5) to balance coherence and diversity. Each of these collective capabilities enable an organization to create public value and can be seen as both a condition and a result of internal processes of learning. The status of each of these collective capabilities reveals the overall capacity of a group to engage in processes of learning and therefore helps (external) agents to specify and strategically select their possible supportive role.

The work of Biesta $(2010,2011)$ places this development of collective capabilities in a broader framework of learning. Biesta's work focuses on different modes of education and learning as well as the function of learning in society and can give us insight in the finality of learning. Biesta makes a distinction between three modes of learning. A first mode of learning is the ever-present idea of qualification: learning as a means to provide someone or a group with the knowledge and skills to do something. This quality of learning forms the basis for the mainstream idea of organized education and is, in our analysis, situated in line with the idea of strengthening the collective capabilities of a group as defined by Baser and Morgan (2008). A second mode of learn- 
ing can be defined as socialization. In this approach a set of structure and rules and the adaptation to existing processes and dominant ideas are crucial. Socialization can be seen as a mode of learning that contributes to the reproduction of existing socio-political order (Biesta, 2010) and its related norms and values. Within collective learning processes this kind of learning usually prioritises the goal to get decisions approved and obtain public support for a particular way of working. The third mode of civic learning can be defined as subjectification. Subjectification entails modes of learning that focus on the emergence of political agency and as such subjectivity (Biesta, 2010). This kind of learning focuses on independency and the importance of reflexivity as the continuous emergence of alternative collective imaginaries and engagement. Biesta further specifies this last mode of learning based on the idea of a pedagogy of interruption. Subjectification is not only about demanding a certain reflexive mode of learning but also about securing the opportunities for new forms of political subjectivity to emerge (Biesta, 2010, 2012). In relation to socially innovative practices this subjectifying mode of learning is crucial to develop a political and transformative potential through collective learning. The different modes of learning often co-exist in processes of collective learning. Their internal balance highly depends on certain requirements of learning that are defined through time.

These different requirements for learning are further theorized by Latour (2004), who introduces a situational understanding of learning and its related time dimension. Originally, Latour describes four requirements for learning to get a better grip on the value of science, knowledge and democracy in our society and how this directly relates to the internal and external dynamics of a group. In Politics of Nature: How to Bring the Sciences into Democracy, Latour (2004) starts from the idea that facts and values can't be defined as exclusive nominators for action. Latour sees both as interrelated concepts that, during a process of learning, lead to a shared reality and definition of the group. Latour distinguishes four requirements that define specific situations of learning. The first two requirements are related to the idea of a group; or, as Vandenabeele and Goorden $(2007$, p. 206) translate: which options do the involved actors take into account? To answer this question, a group needs to go through a process of 'perplexity' (holding on to a broad horizon) and 'consultation' (excluding nobody arbitrarily). The two other requirements relate to strategy, selectivity and the power to arrange in rank and order. Vandenabeele and Goorden (2007) translate this as: which options do the actors experience as being useful? This question can be answered by processes of 'hierarchy' (trying to understand the relationship between new values and what is currently prevailing) and 'institutionalisation' (closing the debate for the time being). A group or collective continuously engage with each of these four requirements. By adding this situational understanding to our theoretical framework, different moments of inclusion and pos- sibilities for engagement get defined and create a basis for further analysis.

By combining the three theories within one theoretical framework (Figure 1), we can develop a situated understanding of collective learning and have a better insight in how the capabilities of a group and the way collective learning is organized changes over time based on to what extent the collective and its supportive relations are constantly (re-)defined by what Latour calls, the "scenarization of the totality", the continuous process of defining the provisional and ever-changing border between inside and outside (Latour, 2004, p. 248). The shared collective capabilities of a group create a clear idea on the possibilities to start and sustain a collective learning trajectory, where the understanding of collective learning as balancing socializing and subjectifying modes of learning tells us something about the quality and finality of learning (and, as such, about its socially innovative potential) and acknowledges this as a changing and balancing endeavour. Lastly, the different requirements for learning can help to understand how a group changes throughout a process of collective learning and opens or closes itself to external support.

The framework shows how this definition of a group, the possibilities for external support, the collective capabilities to organize a collective learning trajectory and the finalities of the applied modes of learning are all interrelated. By integrating these different dimensions we can structurally analyse how a collective learning trajectory and its socially innovative ambitions is organized and changes through time, taking into account the political and institutional context. The trajectory of collective learning is, in both our cases and in line with our framework, defined as the recurrent process during which a (changing) group of people actively and collectively try to (re)define and test how, why, what and in relation to who they are organizing themselves. With regard to external support the framework illustrates three different ways to support collective learning trajectories: (1) by enhancing the collective capacities of a group (can I help a group with one of their five core collective capabilities?), (2) by understanding processes of learning and its socializing and subjectifying dimension (how can I support a subjectifying mode of learning? Can my organization or can I as, e.g., an administrator give other groups the possibility to set up a subjectifying learning trajectory?), as well as (3) fuelling processes of perplexity, consultation, hierarchy and institutionalisation (are there propositions neglected in a group discussion? Can I add propositions based on my expertise, network? How have the participants been selected? Can I avoid arbitrarilyshort-circuiting?).

In order to analyse the two cases based on this theoretical framework three questions were defined that directly relate to the three theories of the framework and their relation with collective learning and social innovation. The following questions have as a goal not to evaluate the cases but to highlight and understand 


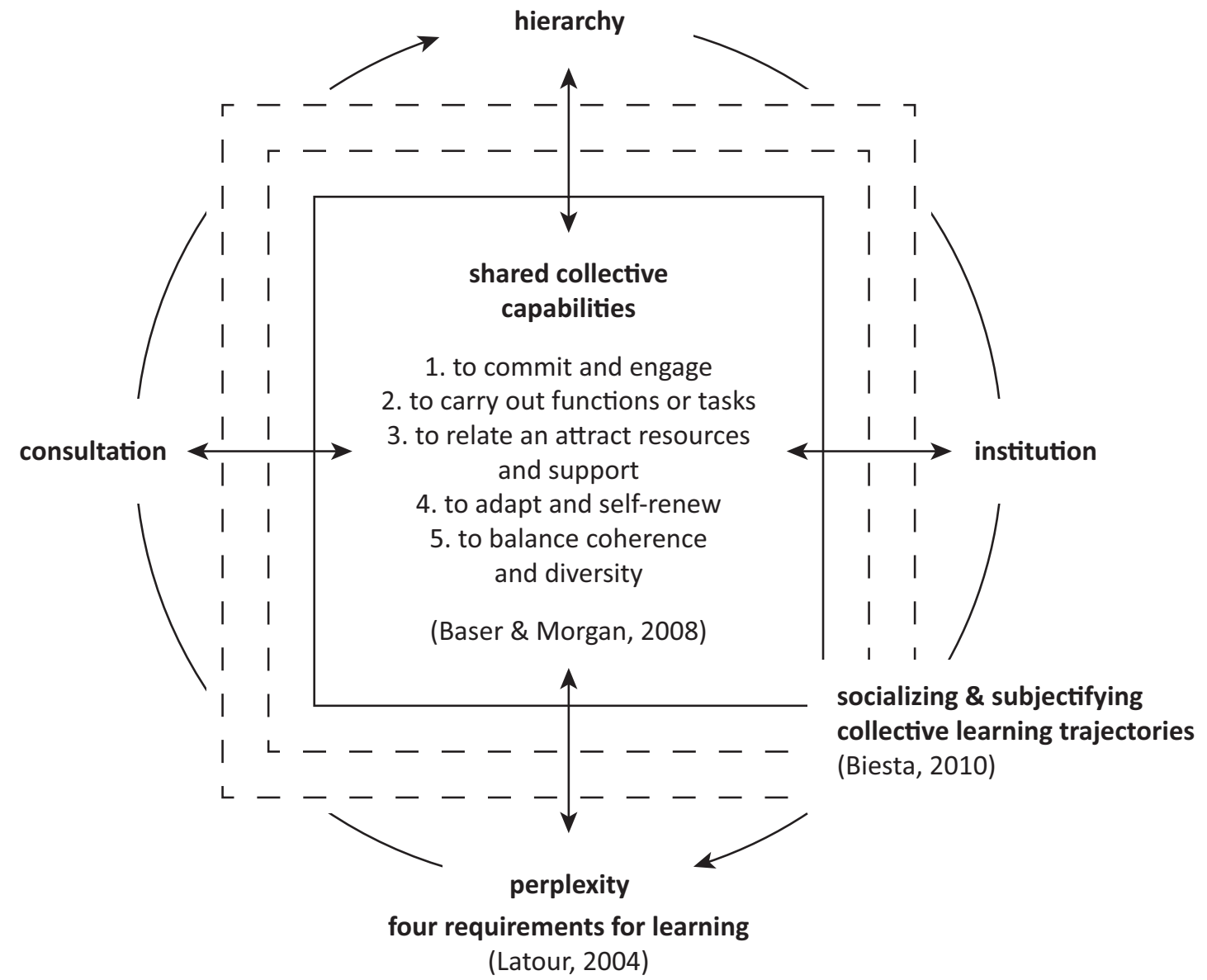

Figure 1. A conceptual framework for a situated understanding of collective learning.

their underlying mechanisms and how these mechanisms can further clarify a situated understanding of collective learning:

1. What are the collective capabilities of a group and how are they developed throughout a process of collective learning?

2. How does the configuration of socializing and subjectifying modes of learning contribute to the socially innovative potential of a trajectory?

3. How did a group deal with the different requirements for learning and how does this influence the socially innovative potential of a trajectory?

\section{Learning from Cases}

\subsection{Living Streets in Ghent}

The Living Streets project can roughly be described as a civil society campaign focused on creating support for a modal shift in the city through concrete temporary interventions and experiments (Figure 2). Yearly, different streets in Ghent are made car-free for two months and transformed into places for experimenting with alternative mobility strategies (bicycle sharing, collective parking, alternative routing, etc.) and the use of public space (creating a greener public space, redefining the space for cars, etc.). In each street, inhabitants are the core of these initiatives. A small group of initiators try to convince neighbours to engage in the experiment and cocreate the activities and specific interventions they want to see implemented. Since the initial idea of the Living Streets project originated at a transition lab of the City of Ghent on future mobility, the different local initiatives have a strong, but often implicit, interrelation with the city-wide debate on new forms of mobility. From the start of the Living Streets project in 2013, it has been Lab van Troje (the Trojan Lab), the organizer of the project, firm ambition to organize a creative laboratory that offers solutions to speed up the process of turning the Ghent area into a sustainable, liveable and climate-neutral region.

The Trojan Lab combines different roles. During the Living Streets campaign, the Trojan Lab provides logistical support for each of the local experiments. On the level of the city the Trojan Lab evaluate the effects of the Living Streets project on changing patterns of mobility and actively investigate and debate the role of temporary use and experiments for local governance systems. Currently, the Trojan Lab is trying to structurally embed this new culture of experimentation in the administrative structures of the City of Ghent. During our research we chose to focus on one of the local collective learning trajectories and selected the case study of the Wasstraat, a street that participated twice, in 2014 and 2015. 


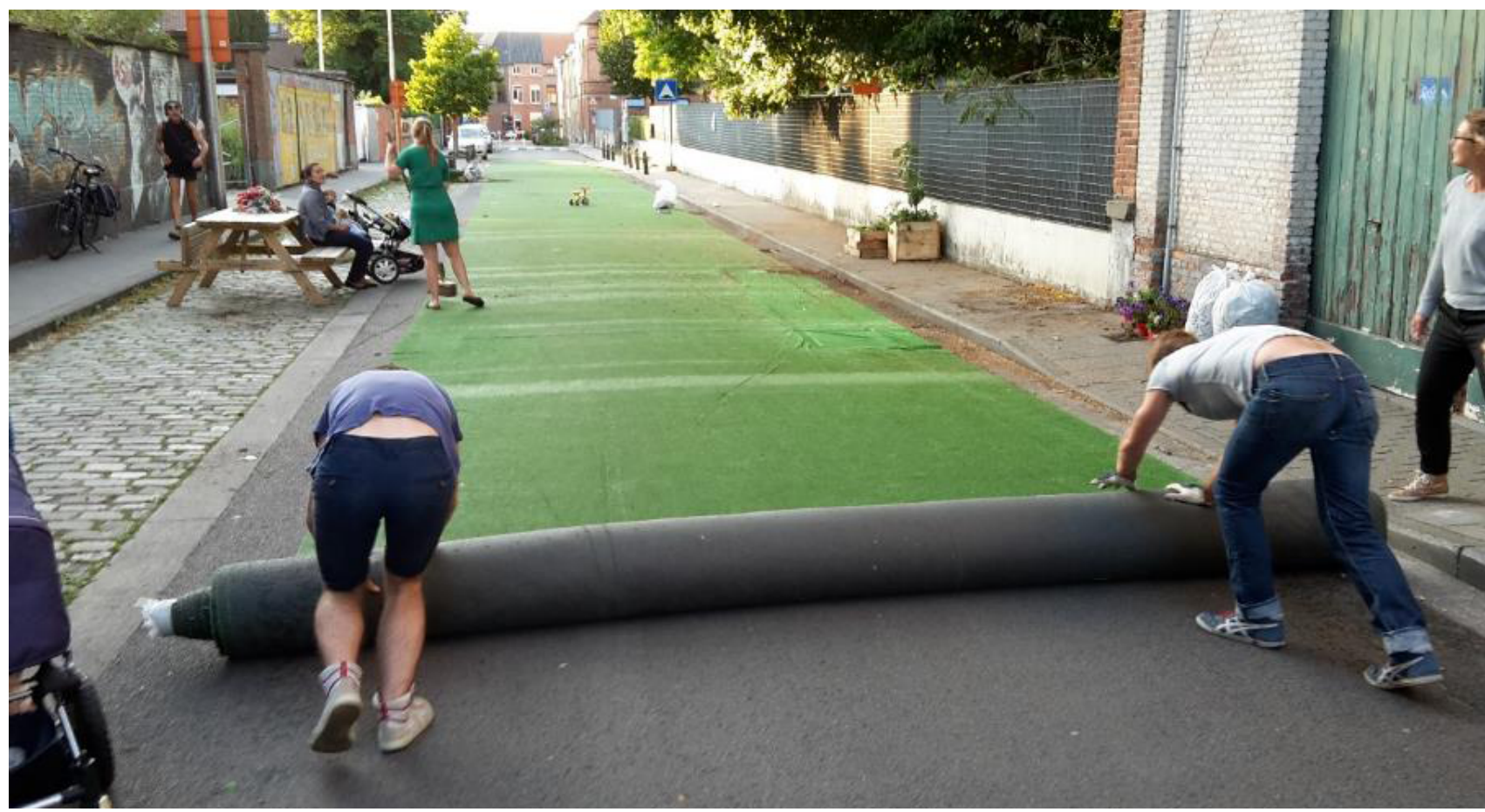

Figure 2. The Living streets as local experiments for car free environments.

The collective learning trajectory in the Wasstraat was mainly centred around the idea of organizing an inclusive trajectory. The initiators wanted to organize an open trajectory that both accepts and provokes unplanned happenings. In order to be as open as possible and true to the experimental nature of Living Streets, the local learning trajectory mainly focused on including the large diversity of inhabitants in the experiment and creating room for changing engagements. In second order, some of the participants of the Living Street Wasstraat were also involved in the coordinating (collective learning) trajectory that would place the different local trajectories in a larger institutional debate hosted by the Trojan Lab. This engagement in a diversity of learning trajectories is mirrored in the organizational structure of the Living Street Wasstraat which is based on a dual structure of on the one hand a small core group of initiators (who worked together with the Trojan Lab and other Living Streets) and on the other hand a large group of neighbours who took part in the local experiment. The local learning trajectory strongly focused on an inclusive approach, i.e., learning by consulting every family in the street and inviting them to participate and by only applying socializing modes of learning as a way to create the right conditions for collective experimentation. During the trajectory basic rules on the use of space, such as timeframes and maintenance logics were defined and the threshold of participation was lowered by guaranteeing the temporary character of the interventions. This approach hardly changed in their participation in 2015.

What are the collective capabilities of the Living Street Wasstraat and how are they developed throughout their process of collective learning?
The capability to balance coherence and diversity was from the beginning of the collective learning trajectory an important aspiration of the organization in order to involve as many neighbours as possible in their temporary experiment. Throughout the trajectory the other capabilities of Baser and Morgan were developed. Most of the collective capabilities were managed in the core group of the initiative. The initiators of the Wasstraat learned to deal with the passivity of certain groups, creating momentum by programming activities and accepting experiments with uncertain outcomes. Throughout the experiment other collective capabilities such as the capability to commit and engage, carry out functions or tasks and attract resources were more and more shared by the bigger group of participating neighbours. Since the Living Street Wasstraat was part of a larger yearly campaign, there was more or less a format on how to organize a local collective learning trajectory and how other external actors and organizations like the Trojan Lab could support this endeavour. The lab created, for instance, a manual on how to start a Living Street. This manual gives the necessary structure for local initiators to start and explore how they can create an own collective trajectory. The lab also supported every living street on a logistical level by negotiating permits with the city, providing contact with supportive enterprises to co-develop experiments, etc. Because of this format the local organization of the Living Street Wasstraat was almost automatically embedded in a larger multi-layered organizational structure. This semi-institutional structure created a direct potential for social innovation by combining a strong local collective learning trajectory that engaged a large diversity of actors with a supra-local collective learning 
trajectory that tried to influence further processes of institutionalization. In order to better understand this potentiality, we must look at the other dimensions of our framework of collective learning.

How does the configuration of socializing and subjectifying modes of learning contribute to the socially innovative potential of the Living Street Wasstraat?

The cooperation between different learning trajectories and their underlying organization created an interesting condition to balance socializing and subjectifying modes of learning. The case of the Wasstraat clearly shows that sustaining the necessary balance between accepting and provoking unplanned happenings could only be achieved thanks to a strategic interchange between street-level and city-level learning trajectories. The organizational structure of different collective learning trajectories made it possible that the Wasstraat, on street-level, decided to create a very open, experimental and subjectifying trajectory, where on city-level, the Lab van Troje chose to run for a more political, governance-oriented and as such socializing trajectory. The balance between both trajectories could be secured because of a strategic interchange that respected the specific definition of each of the collective learning trajectories and the differential importance of socializing and subjectifying modes of learning. The importance of this mutual understanding becomes clear in the following example: right after the second edition of the Living Street Wasstraat, the planning department of the City of Ghent used the wide public support for the Living Streets experiment as an opportunity and legitimation to plan and design some structural changes in the composition of the public space. However, by neglecting the experimental and subjectifying character of the Wasstraat and introducing a more socializing planning mode of learning (designing a plan, finding support, etc.) they failed to set up a common trajectory.

In relation to the social innovative potential of the Living Streets this differentiation in organizational structures, not only based on supporting collective capabilities but also on the importance of balancing subjectifying and socializing modes of learning, seems to be promising. An organizational structure based on different trajectories of collective learning gives the possibility to limit the inherent socializing pressure of processes of institutionalisation on local trajectories of collective learning. Meanwhile a more structural embedment of local learning trajectories in a city-wide discussion gives the possibility to directly influence existing governance structures, bringing a large diversity of social values to the front of the debate. In order to strengthen this relation between local learning trajectories and governance discussions the Trojan Lab organized intermediate sessions where representatives of the local Living Street experiments met and collectively reflected on their local cases as well as the trajectory as a whole. Based on this introduction of an intermediate structure we need to question whether these different layers of the collective learning trajectory really belong to the same learning trajectory or are to be seen as strategic alliances (that strengthen the collective capabilities of different groups and create space for balancing socializing and subjectifying modes of learning).

How did the Living Street Wasstraat deal with the different requirements for learning and how did this influence the socially innovative potential of the trajectory?

On a local level the changes in the group and its collective learning trajectory were limited. Starting from an open and inclusive perspective on membership and experimentation, the Living Street Wasstraat was primarily focused on a continuous engagement with the requirements of perplexity and consultation, trying to gather a diverse group of neighbours and creating the ideal conditions for interchange and open reflection. The requirements of hierarchy and institution and their related discussions mainly centred on implementing temporary interventions. The rules that were defined and the choices made during the collective learning trajectory related to creating the conditions of learning rather than to proposing new solutions or perspectives based on what was learned (this wasn't the case for all the local Living Street trajectories; some initiatives dealt with subsequent reflection on the results of their local experiments).

This limited engagement with the requirements of hierarchy and institution somewhat questions our idea of the socially innovative potential of the local trajectory and its differentiated organizational structure. The local and diverse processes of learning that worked on street-level wasn't reflected in the discussion and process of learning on the level of the city. Although the different results and evaluations of all the local Living Streets experiments were used as an inspiration to challenge and change the mobility policy in the city, local and supra-local trajectories weren't part of the same collective learning trajectory, they didn't share processes of learning; this was illustrated by a limited focus on feedback relations, the inexistence of an agenda shared by all the initiatives and participants and, probably, a different interpretation of what to take into account or what to define as useful.

\subsection{The Eastern Rail Park in Antwerp}

PSO is a completely different story. The case is centred around a partly abandoned railway yard in the north of Antwerp (Figure 3). Although the City of Antwerp decided to develop the site as a parking lot and a zone for events in 2015, different neighbourhood organizations had pleaded for a more public and green use. Throughout the development of the site, a close collaboration between opposing organizations (the city administration of Antwerp and the local neighbourhood associations) and their respective storylines, could never be established, contrary to the Living Streets project in Ghent. Despite this apparent failure, the case shows an interesting learning trajectory as it illustrates how certain events limit the socially innovative potential of collective learning processes and situate it in a larger field of social action. 


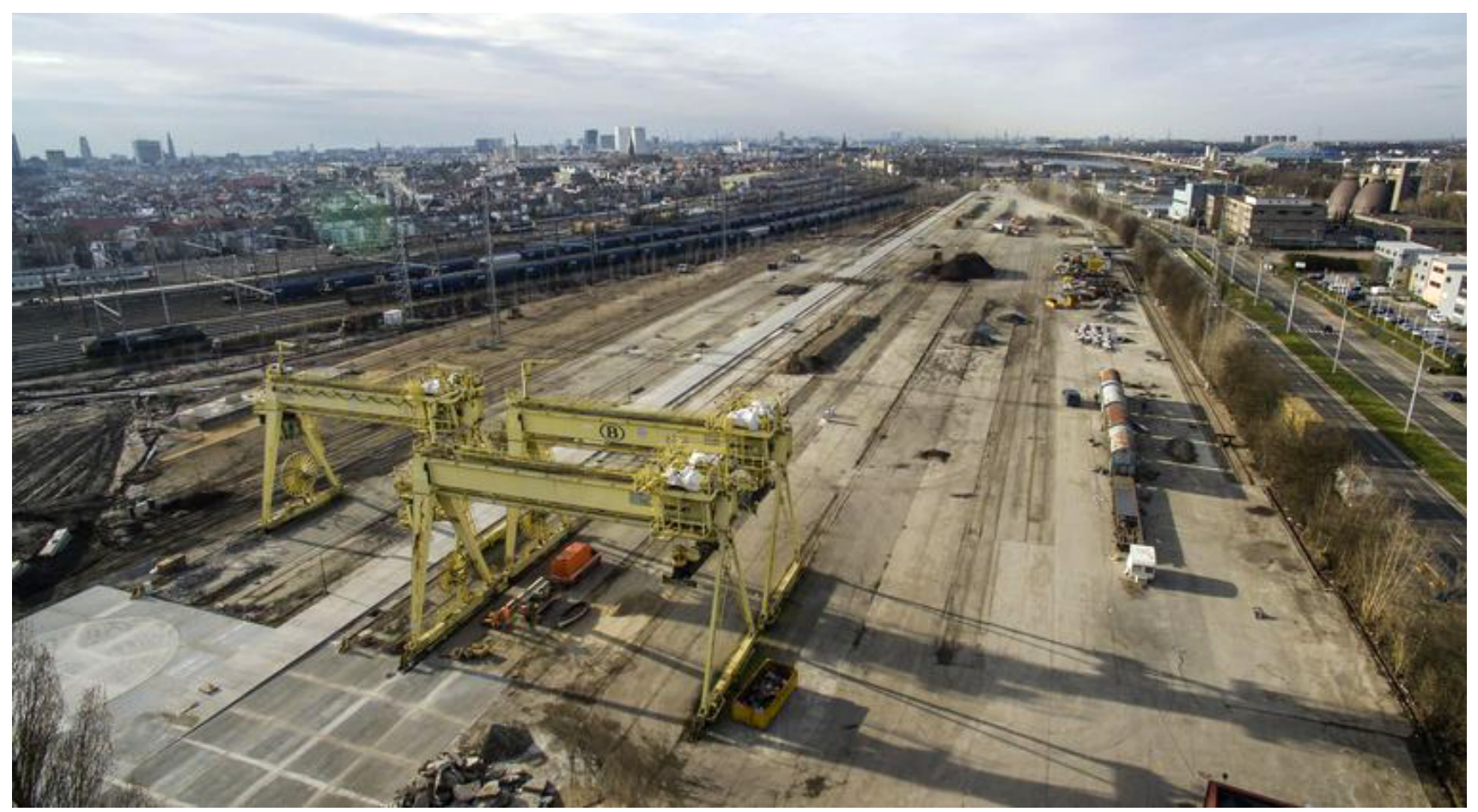

Figure 3. The PSO: An abandoned railway yard in the north of Antwerp.

The collective learning trajectory of PSO was a rather fluctuating process. As an action group PSO highly depended on changing contextual conditions such as the existence of an official vision on the PSO, legal procedures etc. A first reorganization of the group and its learning trajectory was carried out after difficult negotiations with the City on the future of the abandoned railway yard. PSO, at that moment a local neighbourhood committee working on a shared formulation of a vision together with a large diversity of neighbours, decided to create two types of organizations: PSO and Oostnatie. PSO operated as a civil action committee that would challenge the plans of the City in court, while Oostnatie adopted a more cultural profile and claimed and programmed the area in order to show its relevance for neighbourhoodrelated activities and preserve the socially innovative potential of the process. This reorganization gave PSO the possibility to further concentrate on its political and activist role and start a legal procedure against the plans of the City. Creating expertise and involvement to gain wide public support for their cause were their main objectives. This specific definition of the group changed again when the planning conditions of the PSO changed. Indeed, the City of Antwerp had started an exercise on covering the nearby ring road what would change the whole configuration of the site. In order to influence this broader trajectory, PSO and other affected neighbourhood organizations started the Schijnverbond, an umbrella organization that pleaded for a full covering of the ring road. This manoeuvre reopened the debates on membership and hierarchy and consequently redefined the new trajectory of collective learning again aiming to open up the process and give room for shared visioning.
What are the collective capabilities of PSO and how are they developed throughout their process of collective learning?

Throughout the trajectory PSO, its goals and organizational structure were constantly reinterpreted. This clearly influenced the collective capabilities of PSO, with a strong focus on adaptation and self-renewal. The committee can be described as a small activist group embedded in a larger network of experts focused on communication, legal and technical expertise. Their capacity to effectively organize actions is mostly based on the direct and close ties between the core members and their ability to show flexibility in changing conditions. This central position for the capability to adapt and self-renew had a direct effect on the collective learning trajectory of PSO. Even when the group wanted to reach a broader and more diverse group of people, as was the case when different groups joined forces in the Schijnverbond, the actual trajectory of collective learning and the development of further capabilities was not open to members outside the core group of the organization. And so, the socially innovative potential of PSO seems to be rather low when taking into account the way the organization is structured. In order to further understand this limitation, we need to look at the other dimensions of our reflexive framework.

How does the configuration of socializing and subjectifying modes of learning contribute to the socially innovative potential of PSO?

Contrary to the Living Streets the context of learning of PSO isn't primarily defined by an over-arching design process of learning, but directly relates to events and positions that are defined in spite of what is happening on 
a local scale. Collective learning is in the case of PSO not instrumental for processes of institutionalization but directly organizes processes of collective action. This constantly changing context influences the role of learning. Whereas in the case of the Living streets, clearly defined expectations of learning were instrumental in balancing the multiplicity of learning trajectories, the case of PSO shows a clear engagement with mostly subjectifying modes of learning. In the different constellations during its collective learning trajectory, PSO searched for alternatives for ways of working as defined by the government. From the moment more socializing modes of learning were expected, the group changed and reorganized itself, as was the case when a parallel trajectory with Oostnatie was created (an organization that partly works within the borders of the existing institutional order).

This subjectifying way of working can be seen as the result of a more hostile institutional context, but also influences how external actors as planning practitioners can support their collective learning trajectory since the finality of their organization (advocating for an alternative development strategy) isn't widely acknowledged and neither is part of a broader campaign or cooperative system, as was the case for the Living Streets. An engagement with these kinds of initiatives asks for a clearer positioning of external actors, the acknowledgement of the strategic choices behind a certain initiative and relating these choices to the position of their own organization and institutional structures.

How did PSO deal with the different requirements for learning and how did this influence the socially innovative potential of the trajectory?

In the PSO-case, the different requirements for learning are directly related to the strategic choices of the group in reaction to changing conditions of the planning process. The role of perplexity and consultation for instance changed throughout the trajectory. At the start of their existence PSO had a much more inclusive ambition by reaching out to a large diversity of neighbours. From the moment this representative position of PSO was neglected by the City and seen as less relevant in the debate, PSO changed its focus to a more adaptive structure concentrating on technical expertise that would help them to advocate for an alternative future of the site.

Since a cooperation with PSO directly involves the acknowledgement of how they strategically deal with the different requirements for learning (and hence, how they position themselves, what is taken into account, etc.) the different collaborations of PSO with other organizations like Oostnatie and het Schijnverbond were always embedded in a trajectory of collectively defining the structure of learning (taking into account the four requirements for learning). The strategic cooperation with Oostnatie for instance was a clear result of a tactical exercise of organizing a more cooperative and activist trajectory based on a shared understanding of the finality of their actions. In the case of the Living Streets this ex- ercise was already drafted at the beginning of the campaign by the Trojan Lab as the external partner of the local collective learning trajectories. This resulted in a stable environment for learning which diminished the need for strategic action and as such the need to redefine relationships between organizations in a common trajectory of learning. The lack of this stable environment in the case of PSO also limited its potential to organize a more open and diverse collective learning trajectory and consequently influenced the socially innovative capacity of the initiative.

\section{Conclusion}

Both cases showed clear differences in how collective learning and social innovation can interrelate and how each of the dimensions of our reflexive framework directly influence the socially innovative potential of a local learning trajectory. The collective capabilities of a group may be too weak or restricted to actually organize a collective learning trajectory, the context for learning may be too hostile or undefined which leaves no room for balancing socializing and subjectifying modes of learning, or the way a group deals with its requirements for learning is not acknowledged or not actively taken into account in the further process of institutionalization. In order to understand how these different situations can be avoided the case study research presents a situated and multi-layered understanding of collective learning trajectories. Both cases showed how trajectories of collective learning need to be understood in relation to other collective learning trajectories. In the case of the Living Street Wasstraat, the Trojan Lab directly supported the collective capabilities of the group and influenced the way the Wasstraat balanced socializing and subjectifying modes of learning and how it dealt with the different requirements of learning. In the case of PSO, the creation of new and parallel learning trajectories as Oostnatie and the Schijnverbond were a direct reaction to the unsupportive relation with the dominant learning trajectory of the City. This multi-layered understanding of collective learning is to be seen as an additional element to our reflexive framework that concretizes the institutional embeddedness of collective learning trajectories and the possible supportive role of external actors.

The institutional embeddedness of collective learning trajectories directly relates with whether or not the different dimensions of a collective learning trajectory are acknowledged by existing instruments, procedures and external actors. The following reflexive questions, based on the different dimensions of our framework, can help to assess this institutional position. With regard to the collective capabilities of a group, it can be questioned: do planning procedures create room for collectives to organize themselves in order to become active partners or are there specific instruments to strengthen the collective capabilities of a local learning trajectory? 
To balance socializing and subjectifying modes of learning one must reflect if the methods used are only applicable for a subjectifying or socializing mode of learning. When are which kind of methods normally used? Do other actors agree with this? Is there the possibility to have an open debate about it? Engaging with the different requirements of learning, on the other hands, starts from the question: can the requirements of learning for a certain group be acknowledged? And which underlying facts and values are determined in the underlying differences with other trajectories of learning?

The supportive role of external actors seems to enlarge in a multi-layered understanding of collective learning by taking into account the possibility to relate different learning trajectories to one another. Besides taking part in a (pre-existing) collective learning trajectory, a multi-layered understanding creates the possibility to engage in strategic alliances that can strengthen the collective capabilities of a group and form a coherent basis for balancing socializing and subjectifying ways of learning. The possibility to create a supportive context for collective learning introduces new reflexive questions that can help external agents to better define their role and added value in collective learning trajectories: is there a possibility to set up a certain parallel trajectory to support a group on one of their collective capabilities without the need to get involved in a common learning trajectory? Do I have instruments/procedures that can help me with this? Can I guarantee that the outcome of a collective learning trajectory will be respected? How can I limit the influence of existing institutional frameworks in order to create enough room for manoeuvre for local collective learning trajectories to define their own interpretation of hierarchy and institutionalization?

Based on these reflexive questions, that can be seen as new research agendas for researchers and practitioners, it becomes clear how theories from the field of pedagogy and organizational studies can form an interesting perspective for planning practice and research to understand how collective learning trajectories and social innovation interrelate. Although none of the theories directly related to social innovation studies, their situational and multi-layered understanding of collective learning showed how actors can interrelate with trajectories of collective learning, not only through direct involvement but also through creating a supportive context for socially innovative practices. The reflexive framework can give insight in the underlying mechanisms of collective learning and so reduce the imminent threat to misinterpret and co-opt collective learning trajectories and their socially innovative potential. Moreover, a multi-layered understanding of learning and the possibility to relate different learning trajectories to one another based on a clear analysis of their internal requirements for learning and collective capabilities is an interesting tool for engaged actors to enlarge their freedom to act and widen the institutional support for social innovation in planning practice.

\section{Acknowledgements}

The research was supported by a special PhD Fellowship of the Research Foundation-Flanders-and made possible through funding support of the KU Leuven Fund for Fair Open Access. We want to thank the three anonymous referees for their challenging comments on an earlier version of this article.

\section{Conflict of Interests}

The authors declare no conflict of interests.

\section{References}

Albrechts, L. (2012). Reframing strategic spatial planning by using a coproduction perspective. Planning Theory, $12,46-63$.

Albrechts, L. (2015). Ingredients for a more radical strategic spatial planning. Environment and Planning $B$ : Planning and Design, 42(3), 510-525.

Baser, H., \& Morgan, P. (2008). Change, capacity and performance. Maastricht: ECDPM.

Bertolini, L. (2010). Coping with the irreducible uncertainties of planning: An evolutionary approach. In J. Hillier \& P. Healey (Eds.), The Ashgate research companion to planning theory: Conceptual challenges for spatial planning (pp. 413-424). Farnham: Ashgate.

Biesta, G. J. J. (2010). Good education in an age of measurement: Ethics, politics, democracy. Boulder, CO: Paradigm Publishers.

Biesta, G. (2011). Learning democracy in school and society: Education, lifelong learning and the politics of citizenship. Rotterdam: Sense publisher.

Biesta, G. (2012). Becoming public: Public pedagogy, citizenship and the public sphere. Social \& Cultural Geography, 13(7), 683-697.

Brown, V., \& Lambert, J. (2013). Collective learning for transformational change: A guide to collaborative action. Oxon: Routledge.

Cassinari, D., \& Moulaert, F. (2014). Enabling transdisciplinary research on social cohesion in the city: The social polis experience. In E. A. Silva, P. Healey, N. Harris, \& P. Van den Broeck (Eds.), The Routledge handbook of planning research methods (pp. 414-425). London: Routledge.

Chambon, J.-L., David, A., \& Devevey, J.-M. (1982). Les innovations sociales [Social innovations]. Paris: Presses Universitaires de France.

De Laat, M. F., \& Simons, P. R. J. (2002). Collective learning: Theoretical perspectives and ways to support networked learning. European Journal for Vocational Training, 27, 13-24.

Friedmann, J. (1987). Planning in the public domain, from knowledge to action. Princeton, NJ: Princeton University Press.

Friedmann, J. (2011). Insurgencies: Essays in planning theory. London: Routledge. 
Healey, P. (2009). The pragmatic tradition in planning thought. Journal of Planning Education and Research, 28, 277-292.

Healey, P. (2013). Learning the city: Knowledge and translocal assemblage. Planning Theory \& Practice, 14(2), 283-285.

Healey, P., \& Hillier, J. (2008). Introduction. In J. Hillier $\&$ P. Healey (Eds.), Foundations of the planning enterprise. Critical essays in planning theory (Vol. 1, pp. ix-xxvii). Aldershot: Ashgate.

Jessop, B., Moulaert, F., Hulgård, L., \& Hamdouch, A. (2013). Social innovation research: A new stage in innovation analysis? In F. Moulaert, D. MacCallum, A. Mehmood, \& A. Hamdouch (Eds.), The international handbook on social innovation. Collective action, social learning and transdisciplinary research (pp. 110-130). Cheltenham: Edward Elgar.

Kaethler, M., De Blust, S., \& Devos, T. (2017). Ambiguity as agency: Critical opportunists in the neoliberal city. CoDesign, 13(3), 175-186. Kuhk, A., Schreurs, J., \& Dehaene, M. (2015). Collective learning experiences in planning: The potential of experimental living labs. Paper presented at AESOP annual congress, Prague, Czech Republic.

Latour, B. (2004). Politics of nature: How to bring the sciences into democracy. London: Harvard University Press.

MacCallum, D., Moulaert, F., Hillier, J., \& Vicari Haddock, S. (Eds.). (2009). Social innovation and territorial development. Farnham: Ashgate.

Moulaert, F., \& Cabaret, K. (2006). Planning, networks and power relations: Is democratic planning under capitalism possible? Planning Theory, 5(1), 51-70.

Moulaert, F., \& Nussbaumer, J. (2005). Defining the social economy and its governance at the neighbourhood level: A methodological reflection. Urban Studies, 42(11), 2071-2088.

Moulaert, F., MacCallum, D., Mehmood, A., \& Hamdouch, A. (Eds.). (2013). International handbook of social innovation: Collective action, social learning and transdisciplinary Research. Cheltenham: Edward Elgar.

Moulaert, F., Martinelli, F., Swyngedouw, E., \& Gonzalez, S. (2005). Towards alternative model(s) of local innovation. Urban Studies, 42(11), 1969-1990.

Moulaert, F., Van Dyck, B., Khan, A. Z., \& Schreurs, J. (2013). Building a meta-framework to 'address' spatial quality. International Planning Studies, 18(3/4), 389-409.

\section{About the Authors}

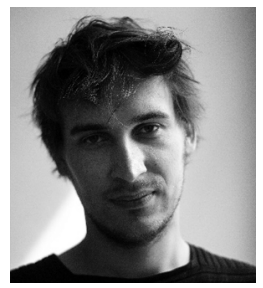

Seppe De Blust is Sociologist and Urban Planner. As a PhD researcher at $\mathrm{KU}$ Leuven he is working on the room for manoeuvre for socially innovative planning practice under post-political conditions. As an active planning practitioner, Seppe co-founded endeavours, an office for socio-spatial research that develops methods, processes and strategies to ensure more people are involved in the process of creating cities (www.endeavours.eu). vation and governance of scale in Austria. In D. MacCallum, F. Moulaert, J. Hillier, \& S. Vicari Haddock (Eds.), Social innovation and territorial development (pp. 131-147). Farnham: Ashgate.

Oosterlynck, S., Van den Broeck, J., Albrechts, L., Moulaert, F., \& Verhetsel, A. (Eds.). (2011). Strategic spatial projects: Catalysts for change. London: Routledge.

Palmås, K., \& von Busch, O. (2015). Quasi-Quisling: Codesign and the assembly of collaborateurs. CoDesign, 11(3/4), 236-249.

Schreurs, J., \& Kuhk, A. (2017). Flanders' spatial (policy) planning in the making: Potential and limits to collaboration as collective learning. Paper presented at AESOP annual congress, Lisbon, Portugal.

Servillo, L., \& Schreurs, J. (2013). Pragmatism and research by design: Epistemological virtues and methodological challenges. International Planning Studies, 18(3/4), 358-371.

Swyngedouw, E. (2008). The multiple and the one. In J. Van den Broeck, F. Moulaert, \& S. Oosterlynck (Eds.), Empowering the planning fields (pp. 135-141). Acco: Leuven.

Van Dyck, B., \& Van den Broeck, P. (2013). Social innovation: A territorial process. In F. Moulaert, D. MacCallum, A. Mehmood, \& A. Hamdouch (Eds.), The international handbook on social innovation. collective action, social learning and transdisciplinary research (pp. 131-141). Cheltenham: Edward Elgar.

Vandenabeele, J., \& Goorden, L. (2007). Participatory planning in protected areas: Exploring the socialscience contribution. In A. E. J. Wals (Ed.), Social learning towards a sustainable world: Principles, perspectives, and praxis (pp. 197-208). Wageningen: Wageningen Academic Publishers.

Vandenabeele, J., Vanassche, E., \& Wildemeersch, W. (2011). Stories of/on citizenship education: A case of participatory planning. International Journal of Lifelong Education, 30(2), 171-185.

Whatmore, S. (2009). Mapping knowledge controversies: Science, democracy and the redistribution of expertise. Progress in Human Geography, 33(5), 587-598.

Wildemeersch, D. (2007). Social learning revisited: Lessons learned from North and South. In A. E. J. Wals (Ed.), Social learning towards a sustainable world: Principles, perspectives, and praxis (pp. 99-116). Wageningen: Wageningen Academic Publishers.
Novy, A., Hammer, E., \& Leubolt, B. (2009). Social inno- 


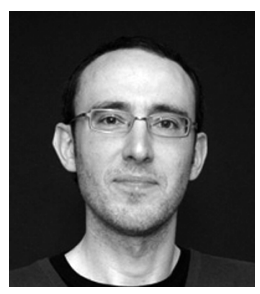

Oswald Devisch is Associate Professor in Urban Design at Hasselt University, Belgium. He is coordinator of the research cluster Spatial Capacity Building and explores themes such as collective learning, casual participation, autonomous urbanisation and the gamification of participation.

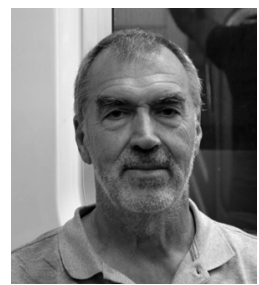

Jan Schreurs is Professor Emeritus at KU Leuven. His research interests are grounded in the will to enhance the spatial qualities of man-made environments. His main focus has always been Place Studies and Typology-Morphology Studies, related to quality, creativity in and innovation by analysis and design, with attention to user involvement as a goal and as means. Bridging gaps between theory and practice has always been a central concern, both in research and in teaching. 